A paper to be presented at the 268th meeting of the

American Institute of Electrical Engineers,

New York, February 9, 1912.

Copyright 1912, By A. I. E. E.

(Subject to final revision for the Transactions.)

\title{
A METHOD OF STUDYING POWER COSTS WITH REFERENCE TO THE LOAD CURVE AND OVERLOAD ECONOMIES
}

\author{
BY GEORGE I. RHODES
}

A great many curves have been presented before the Institute showing the relation between load factor and the cost of power. Some of them were based on very simple relationships between the elements entering into the total cost, and others have been of a purely empirical nature based on actual results. The interrelation of the various items of power cost is necessarily very complicated and dependent to a large measure on the skill and judgment of the engineer in charge. Few plants have been operated at any considerable range of load factor under the same operating engin zer. It has been the privilege of the author to work up many of the curves presented to this Institute and he has been led to the belief that a more extended study of the subject is necessary in order to find the means of properly comparing the costs of power in different plants operating under different management, load conditions, coal costs, labor costs, and other circumstances.

By far the largest and most important item entering into the cost of power is that of fuel, which is determined by the cost of coal and the operating economies of the prime movers and the boilers. The type of load carried has a large influence on the thermal efficiency. A fluctuating load requires more coal than an equal steady load. A load extending throughout the day with large peaks morning and night, requires more fuel than a steady and uniform load lasting for a part of the day.

In order to deduce operating economies from test results, 
taking into account all of the items producing variation, a certain classification of losses, etc., is desirable.

\section{Relation of Load Factor to Operating Power Costs}

In electrical apparatus the relation between input and output of energy is made up of three items:

A. An input proportional to the output, the ratio betwen which depends on the theoretical maximum efficiency of transformation. In electrical apparatus this efficiency is unity because there are no losses which are theoretically unavoidable.

B. An input sufficient to supply all the no load losses, namely, excitation, core loss, friction, windage, etc.

C. An input proportional to the square of the load which supplies the various load losses, resistance, magnetic, etc.

In thermodynamic apparatus, however, this simple relationship between the input and the output has not been demonstrated as completely as is the case in electrical energy transforming devices. It is probable that the closeness of such a relationship is by no means as exact. However, the general formation of the curves obtained from tests leads one to expect that such a corelation of the losses and the load does exist with a greater or less degree of approximation. It is not as easy to determine thermodynamic as electrical losses.

However, the losses in heat engines may be classified as follows, similarly to the electrical classification:

A. An input proportional to the load, the ratio depending on the maximum theoretical efficiency.

In steam boilers this efficiency may closely approach unity, the only unavoidable source of loss being in the fact that the flue gas temperature must be at least equal to that of the steam.

In prime movers the maximum ideal efficiency is that of the Carnot cycle determined by the steam temperature and the vacuum. This efficiency can never be equalled in practice, but the losses over and above those necessary for this cycle can be taken care of as load losses.

B. An input sufficient to cover all radiation, friction, windage and other no-load losses.

These losses are sensibly constant at all loads and may thus be measured as no-load losses in either boiler or prime mover. The variation from constancy may be taken care of by the load losses.

C. An input dependent upon the losses caused by the load. 
In a boiler and furnace the load losses are practically all in the flue gases. As the load is increased it is necessary to pass more air through the fire, thus increasing the volume of the flue gases in proportion approximately equal to the increase in the load. The temperature of the flue gases is also increased above that of the steam in a similar proportion. It is thus evident that the volume and the temperature of gases each being increased approximately in direct proportion to the load, the losses thus occasioned are closely proportional to the square of the load. There are other load losses but they are relatively small.

In a prime mover having a perfect cycle there is a certain amount of heat rejected to the condenser. It is probable that at no load, a slight additional load will be developed at an efficiency closely approximating the ideal. With increase in load the cycle departs more and more from this ideal, the increased loss per unit of input being somewhat in proportion to the load. Since there is an increased heat input proportional to the load, the total load losses will increase as the square of the load.

There is no doubt but that this load, squared, relationship is far less exact in thermodynamic than in electrical apparatus. Tests of heat apparatus are by no means as accurate or as consistent as those of electrical machines, because the conditions under which they are made are far less constant and controllable. Under normal operation these conditions are still more variable. It would thus appear that the assumption of the classification of input to steam apparatus on the basis outlined is warranted for purposes of studying the probable relationship of power cost and load.

Thus if

$l=$ the output of the apparatus

$R=$ " rating of the apparatus

$A=$ " input proportional to the load

$B=$ " input independent of the load per unit rating

$C=$ " input proportional to the square of the load per unit rating

$h=$ " total input

$$
h=A l+B R+C R \frac{l^{2}}{R^{2}}=A l+B R+C \frac{l^{2}}{R}
$$

If a subscript $P$ indicates references to the prime mover 
equipment, and a subscript $B$ indicates reference to the boiler equipment, the input to the engine room of a single unit is

$$
h_{\mathrm{P}}=A_{\mathrm{P}} l_{\mathrm{P}}+B_{\mathrm{P}} R_{\mathrm{P}}+C_{\mathrm{P}} \frac{l^{2} \mathrm{p}}{k_{\mathrm{P}}}
$$

At full load $h_{\mathrm{P}}=R_{\mathrm{P}}\left(A_{\mathrm{P}}+B_{\mathrm{P}}+C_{\mathrm{P}}\right)=R_{\mathrm{P}} H_{\mathrm{P}}$ If the boiler room rating $=r R_{\mathrm{P}} H_{\mathrm{P}}$

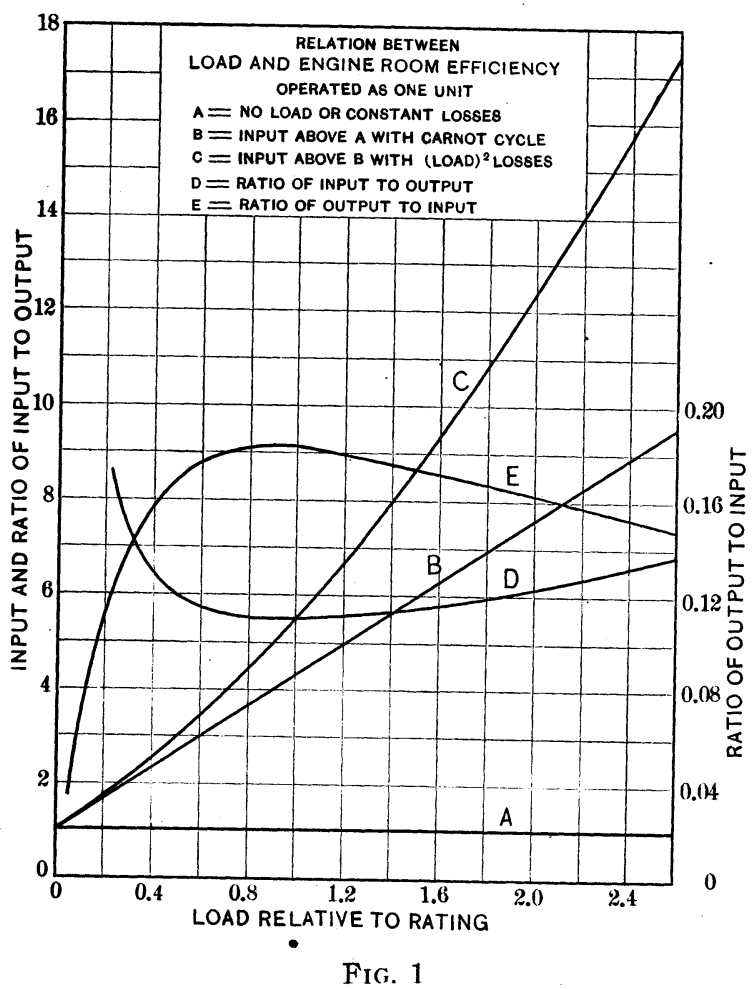

The input to the boiler room of a single unit is

$$
h_{\mathrm{B}}=A_{\mathrm{B}} l_{\mathrm{B}}+B_{\mathrm{B}} R_{\mathrm{P}}+C_{\mathrm{B}} \frac{l^{2}{ }_{\mathrm{B}}}{R_{\mathrm{B}}}=A_{\mathrm{B}} h_{\mathrm{P}}+B_{\mathrm{B}} r R_{\mathrm{P}} H_{\mathrm{P}}+C_{\mathrm{B}} \frac{h^{2} \mathrm{P}}{r R_{\mathrm{P}} H_{\mathrm{P}}}
$$

The constants of these equations may be determined from a study. of the net heat energy required by the engine room and by the boiler room of any plant. 
As an illustration of the meaning of these equations Figs. 1 and 2 will suffice. Fig. 1 , curve $C$, is plotted for the case where $A_{\mathrm{P}}=3.30, B_{\mathrm{P}}=1.00, C_{\mathrm{P}}=1.20$. Curves are also shown which give the usual method of expressing the efficiency of the unit, in input per unit output $(D)$ and its reciprocal $(E)$. It will be noted that there is nothing unusual about these curves; in fact they are quite typical of what may be expected for a turbine room. There is a marked rise in heat consumption per unit

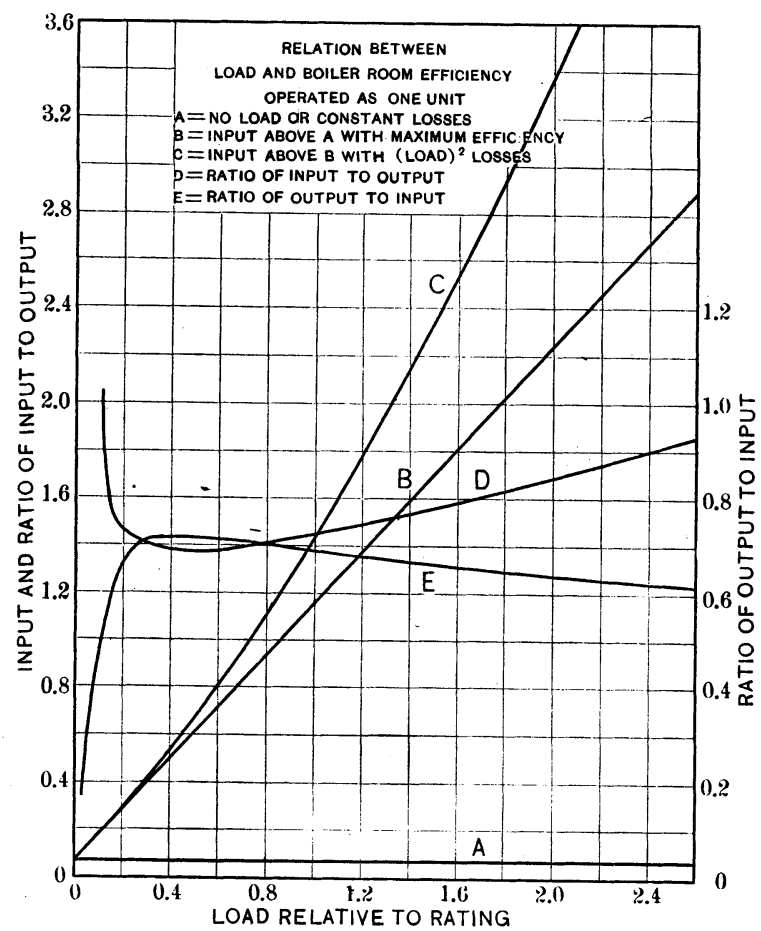

FIG. 2

output at light loads due to unavoidable no-load losses in the unit itself and in its auxiliaries. There is a similar but much less rapid increase at overloads due to the load losses and the inability of the condenser to maintain its full vacuum. Fig. 2 is plotted for the case where $A_{\mathrm{B}}=1.09, B_{\mathrm{B}}=0.07, C_{\mathrm{B}}=0.29$. Here again the curves well represent the condition in a boiler room as normally operated.

To determine the combined efficiency of the plant it is neces- 
sary to develop equation (2) so that its only variable is that of the load on the prime movers. This developed equation is of the form

$$
\dot{h_{\mathrm{B}}}=K_{0} R_{\mathrm{P}}+K_{1} l_{\mathrm{P}}+K_{2} \frac{l_{\mathrm{P}}{ }^{2}}{R_{\mathrm{P}}}+K_{3} \frac{l_{\mathrm{P}}{ }^{3}}{R_{\mathrm{P}}{ }^{2}}+K_{4} \frac{l_{\mathrm{P}}{ }^{4}}{R_{\mathrm{P}}{ }^{3}}
$$

With the engine room and boiler room of the constants given above, and the additional constant $r=l$, or the rating of the

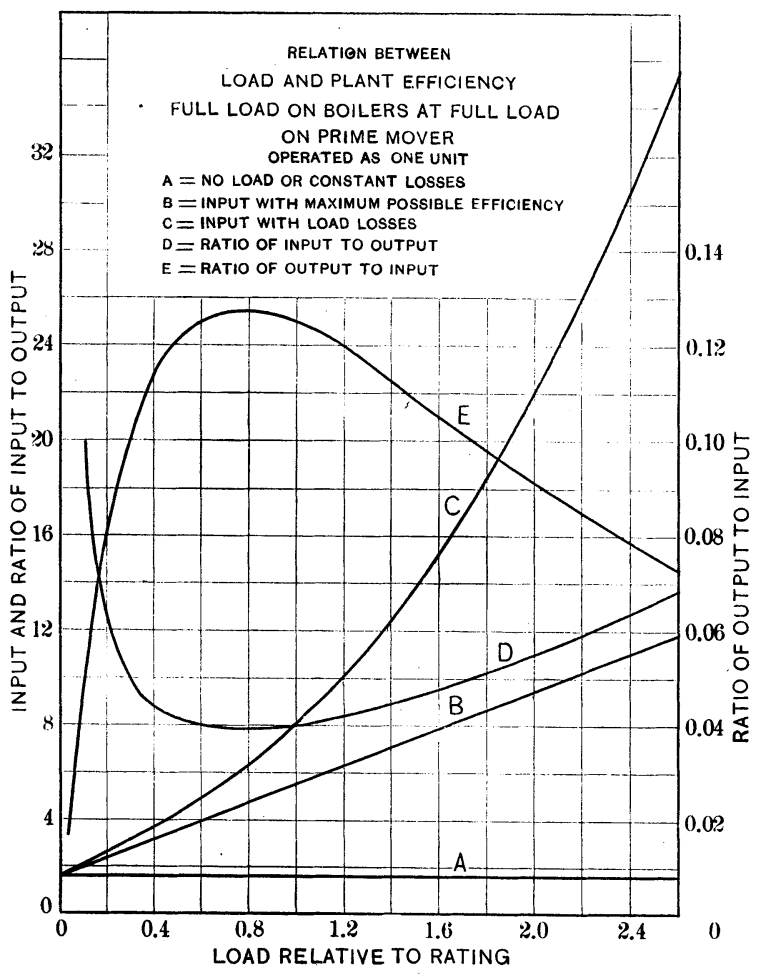

FIG. 3

boiler room such that it will deliver its rated output for full load on the engine room, the combined efficiencies are as shown on Fig. 3.

The equation becomes

$$
h_{\mathrm{B}}=1.55 R_{\mathrm{P}}+3.95 l_{\mathrm{P}}+2.01 \frac{l_{\mathrm{P}}{ }^{2}}{R_{\mathrm{P}}}+0.42 \frac{l_{\mathrm{P}}{ }^{3}}{R_{\mathrm{P}}{ }^{2}}+0.08 \frac{l_{\mathrm{P}}{ }^{4}}{R_{\mathrm{P}}{ }^{3}}
$$

Here as before the curves are quite normal. 
In any actual plant, however, the operation is not as one unit. There are about five units in a well designed plant and no more are operated than are necessary to carry the load economically. Fig. 4 shows the relation between load and efficiency of a turbine room of five units, each having the characteristics given above. It will be noted that there is a succession of curves each corresponding to the number of units running. It is probable that at any time when less than the full equipment is running certain

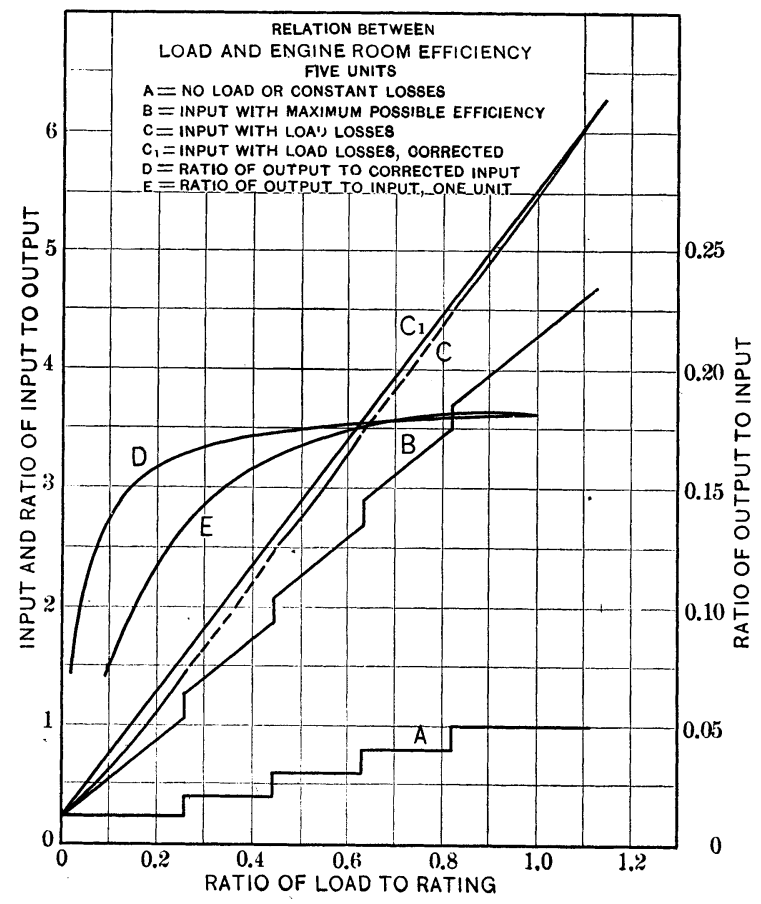

FIG. 4

additional steam is being used for purposes of warming up units or turning them over for adjustment. A straight line extending from a point corresponding to the input of one unit at no load to another corresponding to all units at full load will probably give a close approximation to the actual amount of energy used. For this particular case the equation is

$$
h_{\mathrm{P}}=0.2 R_{\mathrm{P}}+5.3 l_{\mathrm{P}}
$$


The general equation is

$$
h_{\mathrm{p}}=\frac{B_{\mathrm{p}} R_{\mathrm{p}}}{N}+\left[\begin{array}{c}
H_{\mathrm{P}}-\cdots \\
N
\end{array}\right] l_{\mathrm{p}}
$$

It will be noted from the curves $D$ and $E$, Fig. 4 , that there is a very material saving due to having several units, each carrying its proper load.

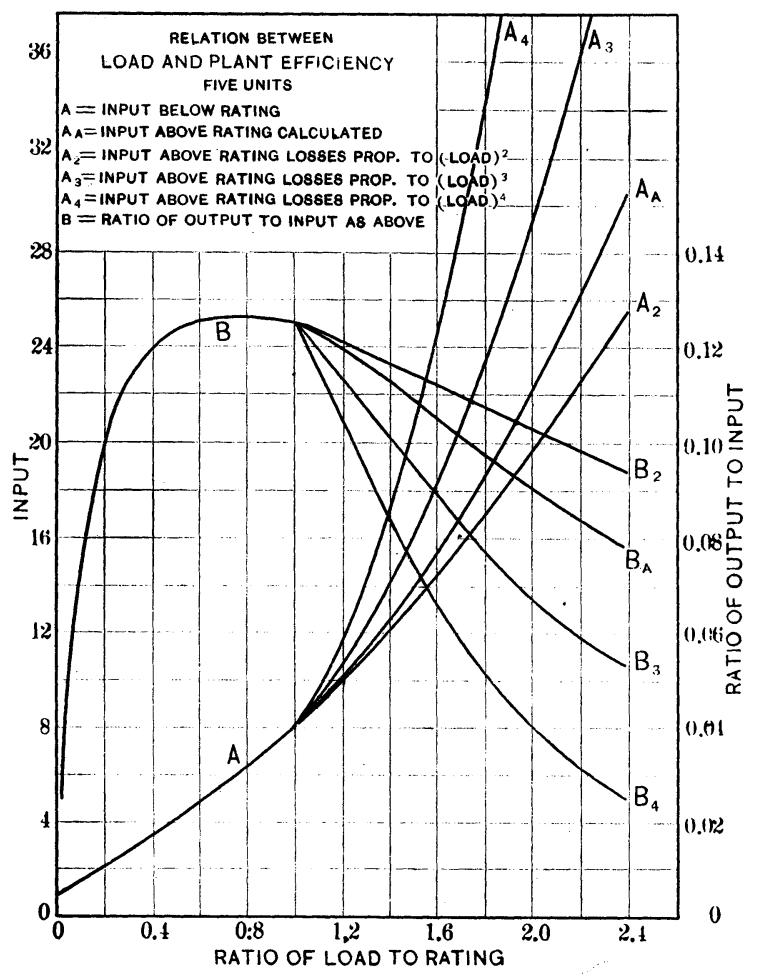

Fig. 5

In the boiler room the difficulty of starting up cold boilers practically necessitates keeping them under pressure and with banked fires in the furnace at times of light load. Accordingly the efficiency of the boiler room is not materially affected by the number of units and the equation (2) may be considered as applying in all cases.

Substituting values from equation (4) into equation (2) will 
give the relation between load on the plant and boiler room input for a plant with several units.

For the case used above the equation becomes

$$
h_{\mathrm{B}}=0.62 R_{\mathrm{P}}+5.90 l_{\mathrm{P}}+1.48 \frac{l_{\mathrm{P}}^{2}}{R}
$$

This relationship is shown by curve $A$ Fig. 5 . When the plant is overloaded the relationship is the same as for a plant of a single unit and is shown in curve $A_{\mathrm{A}}$. The other curves represent the input when the losses at overload are proportional to the square, cube and fourth power of the load.

In any plant the load varies both momentarily, due to fluctuations, and hourly, accordingly to a more or less well defined load curve. On account of the curved line relationship between rate of input and load, the total input over any period will differ from the input corresponding to the average load over that period.

If $H=$ the total energy supplied

$$
\begin{aligned}
H=\int_{0}^{\mathrm{T}} h_{\mathrm{B}} d t & =K_{0} R_{0} T+\dot{K_{1}} \int_{0}^{\mathrm{T}} l_{\mathrm{P}} d t+ \\
& \frac{K_{2}}{R_{\mathrm{P}}} \int_{0}^{\mathrm{T}} l_{\mathrm{P}}{ }^{2} d t+\frac{K_{3}}{R_{\mathrm{P}}{ }^{2}} \int_{0}^{\mathrm{T}} l_{\mathrm{P}}^{3} d t+\frac{K_{4}}{R_{\mathrm{P}}{ }^{3}} \int l^{4} d t
\end{aligned}
$$

$\int_{0}^{\mathrm{T}} l d t=$ total output $=$ average load into time.

$$
=L_{\mathrm{A}}{ }^{\mathrm{T}} \text { where } L_{\mathrm{A}}=\text { average load }
$$

$\begin{aligned} \int_{0}^{\mathrm{T}} l^{2} d t & =\text { the time integral of the square of the load. } \\ & =L_{\mathrm{A} 2} T \text { where } L_{\mathrm{A} 2}=\text { mean square of the load. }\end{aligned}$

$\int_{0}^{\mathrm{T}} l^{3} d t=L_{\mathrm{A} 3} T$ where $L_{\mathrm{A} 3}=$ mean cube of the load.

$\int_{0}^{\mathrm{T}} l^{4} d t=L_{\mathrm{A} 4} T$ where $L_{\mathrm{A} 4}=$ mean fourth power of the load.

Thus

$$
H=K_{0} R_{\mathrm{P}} T+K_{1} L_{\mathrm{A}} T+\frac{K_{2} L_{\mathrm{A} 2} T}{R_{\mathrm{P}}}+\frac{K_{3} L_{\mathrm{A} 3} T}{R_{\mathbf{P}}{ }^{2}}+\frac{K_{4} L_{\mathrm{A} 4} T}{R_{\mathbf{P}}{ }^{3}}
$$


If all units are in kilowatts, kilowatt-hours and hours, $H$ is in kilowatt-hours.

In order properly to appreciate the meaning of this equation it is necessary to apply it to a particular case. For a normal load curve having an average load during the year of about 40 per cent of the maximum hour the mean square load $=16$ $(1.06)^{4}$ per cent.

For a 40 per cent steady load the heat input is

$$
h_{\mathrm{B}}=[0.63+(5.90 \times 0.4)+(1.49 \times 0.16)] R_{\mathrm{P}}=3.23 R_{\mathrm{P}}
$$

For a 40 per cent load curve as above

$$
h_{\mathrm{B}}=\left[0.63+(5.90 \times 0.4)+\left(1.49 \times 0.16 \times(1.06)^{4}\right)\right] R_{\mathrm{P}}=3.30 R_{\mathrm{P}}
$$

The small difference observed here is due to the fact that there is but little curvature for loads below rating. With greater curvature the difference would be greater.

In all of the above relationships input and output are expressed in the same unit, namely, kilowatts or kilowatt-hours. Coal is purchased by the ton in the great majority of plants, but the practice of purchase on the B.t.u. basis is becoming more and more prevalent. In the vicinity of New York, heat in the form of coal costs approximately 9,750,000 B.t.u. per dollar, which translated into kilowatt-hours is 0.350 mills per $\mathrm{kw}-\mathrm{hr}$. in the coal. Expressing coal costs in this manner allows the transformation of the above equations to dollars and cents.

The division of the other items into classes, depending on different functions of the load, is far more difficult than that of coal. Here the skill and judgment of the operating engineer is the most important factor. However, it is certain that were the plant to be maintained at all times ready for instant service and yet deliver no energy, there would be a very considerable cost for labor and supplies to take care of the no-load losses, and of the maintenance for instant service. This cost corresponds to the no-load losses in the apparatus. It is similarly certain that the delivery of energy requires additional labor and supplies in an amount measured by the energy delivered. If the plant is overloaded there are additional costs occasioned by the more careful supervision required by overloaded apparatus, and the maintenance costs, which in all apparatus increase at a rate faster than that of the coal.

The determination of the proportions between these classes of costs is by no means a simple matter. Experience alone can 
give such a determination, but the author believes that a classification based on the following outline will give a fair working basis for comparison.

\section{Loads Below Rating}

Coal. Proportioned as in equations (2) and (4).

Lubrication, supplies, water. Proportioned as per steam for one unit (1).

Coal and ash handling maintenance. Independent of load and rating.

Coal and ash handling operation. Proportioned as per coal for one unit (2) and (1).

Boiler room maintenance. Ditto.

Boiler room operation. Ditto.

Engine room maintenance. Proportioned as per steam for one unit (1).

Engine room operation. Ditto.

Electrical maintenance. Independent of load or rating.

Electrical operation. Ditto.

The following table is deduced from data given in "Notes on the Cost of Power" H. G. Stott, Transactions A.I.E.E., Vol. XXVII, p. 283. The classification is made to correspond with that outlined above and the constants for the equations are given in mills per hour per kilowatt rating. In the division into classes it was assumed that the load factor was 50 per cent and that the shape of the curve was such that the mean square of the load was equal to the square of the mean load multiplied by $(1.05)^{4}$, the mean cube equal to the cube of the mean multiplied by $(1.05)^{6}$, etc. The usual types of load curves have similar constants or characteristics.

OPERATION \& MAINTENANCE COST OF POWER

Steam Turbine Plant. Loads Below Rating MILls PER HOUR PER KW. Rating

\begin{tabular}{|c|c|c|c|c|c|c|}
\hline \multirow{2}{*}{ Item } & \multirow{2}{*}{$\begin{array}{c}\text { From Table } \\
\text { Mills per } \\
\text { Kw.-hr. } \\
50 \text { per cent. } \\
\text { L. F. }\end{array}$} & \multicolumn{5}{|c|}{ Constants in Equations } \\
\hline & & $K_{0}$ & $K_{1}$ & $K_{2}$ & $K_{\mathbf{3}}$ & $K_{4}$ \\
\hline Coal............. & & 0.217 & 2.065 & 0.521 & & \\
\hline Lubrication Water Sup & 0.078 & 0.013 & 0.043 & 0.016 & & \\
\hline Coal!\& Ash. Hand. Maint . & 0.030 & 0.015 & $\ldots \ldots$ & $\ldots \ldots$ & & - \\
\hline 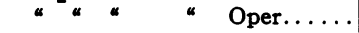 & 0.170 & 0.031 & 0.080 & 0.040 & 0.009 & 0.001 \\
\hline Boiler Room Maint... & 0.238 & 0.044 & 0.111 & 0.057 & 0.012 & 0.002 \\
\hline Oper.. . & 0.371 & 0.068 & 0.174 & 0.089 & 0.018 & 0.003 \\
\hline Turbine Room Maint.. . . & 0.028 & 0.005 & 0.016 & 0.006 & $\ldots \ldots$ & . \\
\hline « Oper.... & 0.075 & 0.013 & 0.041 & 0.015 & & \\
\hline Electrical Maint.. & 0.062 & 0.031 & $\ldots$ & $\cdots$ & $\ldots \ldots$ & $\ldots$ \\
\hline « Oper....... & 0.139 & 0.070 & & & $\ldots \ldots$ & $\ldots \ldots$ \\
\hline Total, except coal... & 1.191 & 0.290 & 0.465 & 0.223 & 0.039 & 0.006 \\
\hline * with & $\ldots \ldots$ & 0.507 & 2.530 & 0.744 & 0.039 & 0.006 \\
\hline & I & OVE $R$ & IING & & & \\
\hline Coal.. & $\ldots \ldots$ & 0.543 & 1.381 & 0.704 & 0.147 & 0.028 \\
\hline Total with coal $\ldots \ldots \ldots \ldots$ & $\ldots \ldots$ & 0.833 & 1.846 & 0.927 & 0.186 & 0.034 \\
\hline
\end{tabular}


Fig. 6 shows graphically the relation between cost and load factor under ordinary conditions of load variation as well as for steady load equal to the average. It will be noted that the increase in cost caused by the varying load is not very large, being only about 2 per cent. at 40 per cent. load factor. In a plant having greater load losses this difference would be greater.

Effect of Poor Economy at Over-loads on the Cost of POWER

In a plant.whose rating is equal to the maximum hour the operation and maintenance costs, exclusive of coal, are, in mills per hour (from above table)

$$
0.290 R+0.465 L_{\mathrm{A}}+0.223 \frac{L_{\mathrm{A} 2}}{R}+0.039 \frac{L_{\mathrm{A} 3}}{R^{2}}+0.006 \frac{L_{\mathrm{A} 4}}{R^{3}}
$$

It is probable that the items of coal and ash handling maintenance and electrical maintenance and operation would be unaffected by the size of the plant, provided it is to carry the same load. In all other items the effect of reduction in the size of the plant to carry any given load is taken care of by the increased steam and coal consumption.

Thus $M=$ the maximum hour load.

The cost of operation and maintenance, exclusive of coal, per hour per kilowatt maximum hour becomes

$$
\begin{aligned}
0.116+0.174 \frac{R}{M}+0.465 L_{\mathrm{A}}+0.223 \frac{M L_{\mathrm{A} 2}}{R}+ \\
0.039 \frac{M^{2} L_{\mathrm{A} 3}}{R^{2}}+0.006 \frac{M^{3} L_{\mathrm{A} 4}}{R^{3}}
\end{aligned}
$$

The cost of coal is

$$
0.217 \frac{R}{M}+2.065 L_{\mathrm{A}}+0.521 \frac{M L_{\mathrm{A} 2}}{R} \quad \text { when underloaded }
$$

and

$0.543 \frac{R}{M}+1.381 L_{\mathrm{A}}+0.704 \frac{M L_{\mathrm{A} 2}}{R}+0.147 \frac{M^{2} L_{\mathrm{A} 3}}{R^{2}}+0.028 \frac{M^{3} L_{\mathrm{A} 4}}{R^{3}}$

when overloaded.

In any plant it would be possible to increase the maximum hour capacity by an expenditure per kitowatt much less than 
the original cost of the plant. Conversely, if a plant is designed with smaller normal rating but with the same maximum hour capacity secured even by wasteful use of steam or fuel the cost per kilowatt maximum hour will be less than that of the first plant, but not in the same proportion as their relative ratings. Thus let it be assumed that a plant costs $\$ 80$ per kilowatt of normal rating and that the overload capacity can be increased to any reasonable extent by a further expenditure of $\$ 40$ per

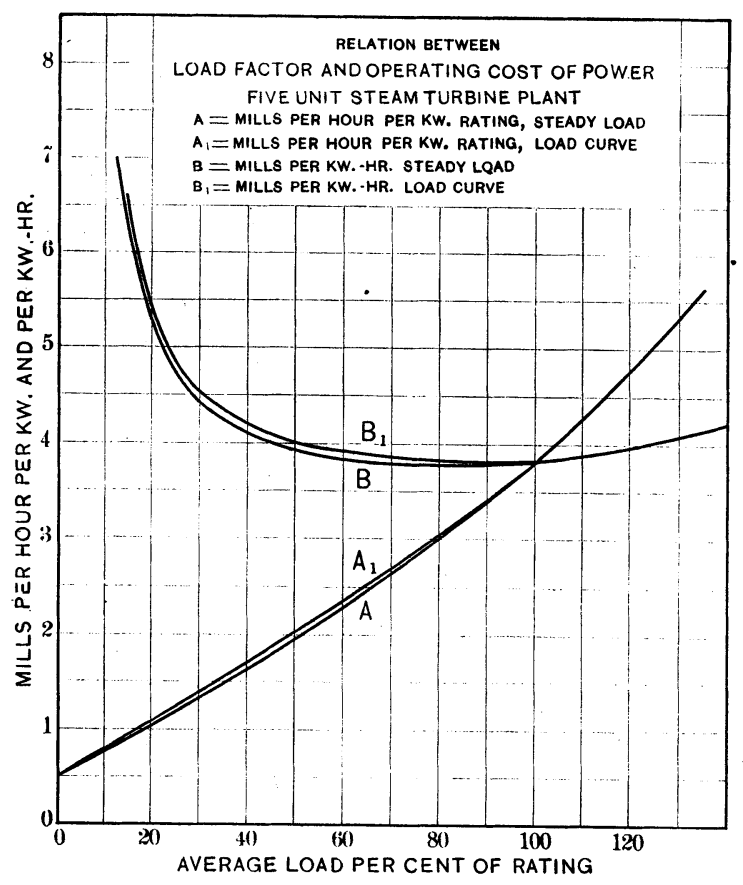

FIG. 6

kilowatt. It would thus appear that the cost of such a plant per kilowatt maximum hour capacity would be

$$
\$ 40+\$ 40 \frac{R}{M}
$$

If fixed charges are at 12 per cent. per annum they will be at the rate of

$$
0.548+0.548 \frac{R}{M}
$$

mills per hour per maximum hour kilowatt. 
If a study is made of any given load curve it is possible from the foregoing equations to determine the effect on the total cost of power, of reducing the nominal rating of the plant but with the same maximum hour capacity. If the rate of increase of load losses at overloads is given varying magnitudes an idea may be gained of the extent to which poor economy at overloads may be carried and still reduce the total cost of power. To do this the various items of load losses may be combined into one, which may be taken as varying as the square, cube, or even fourth power of the load (See Fig. 5).

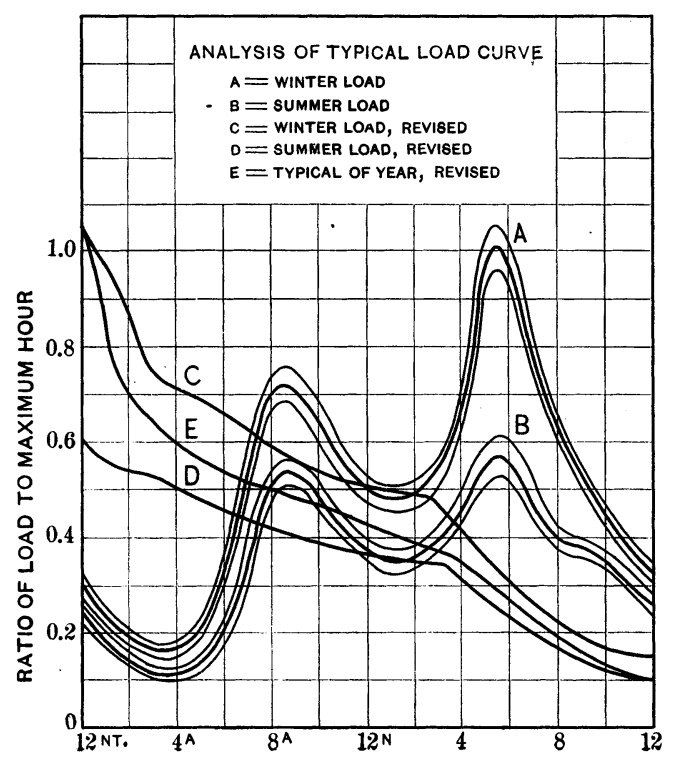

FIg. 7

It is evident that to make such an investigation a very complete analysis of the load needs to be made on the following basis:

$A=$ The hours per year that the load exceeds various amounts.

$B=$ The average load during all these periods.

$C=$ The average square of the load during these periods.

$D=$ The average cube of the load during these periods.

$E=$ The average fourth power of the load during these periods.

Similarly the same information is needed covering the rest of the energy generated, that is, when the load is less than these various amounts taken for comparison. 
During the periods when the load exceeds any amount the costs may be determined from the overload equation of the plant whose rating is that amount. During the other periods the underload equation for this same size plant will determine the costs.

Fig. 7 shows what may be considered as a typical city load curve, the heavy lines showing the mean load, and the lighter lines the limits of fluctuation. If the abscissas of these curves are combined as in curves $C$ and $D$ the curve then represents the hours per day that the load exceeds the value of the ordinate at any point. The curve $E$ is the probable curve covering the entire year. It will be noted that such a curve takes into ac-

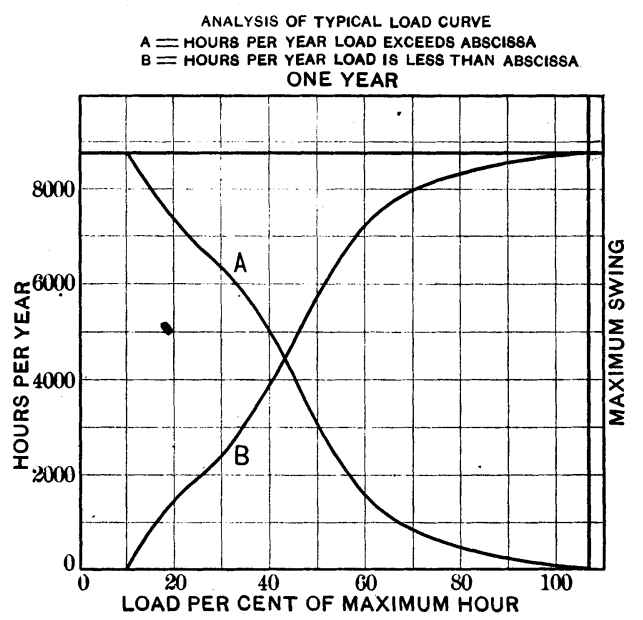

Fig. 8

count not only the hourly variations but also the momentary fluctuations.

Fig. 8 shows the hours per year, corresponding to Fig. 7, that the load exceeds or is less than any given amount. Fig. 9 shows the time integrals of the load (kw-hr.), the square of the load, etc., for all loads exceeding various amounts. Fig. 10 gives this same information for the loads below these amounts. There is thus a complete analysis of a typical city load curve, which applied to equations developed above will make possible the determination of the overload capacity corresponding to the minimum total cost of power.

Figs. 2, 11 and 12, show in detail the cost of generating power 


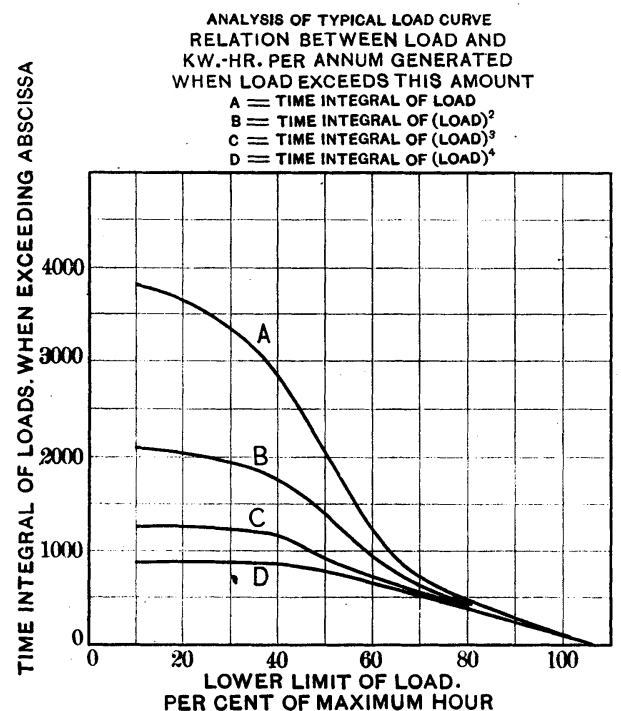

FIG. 9

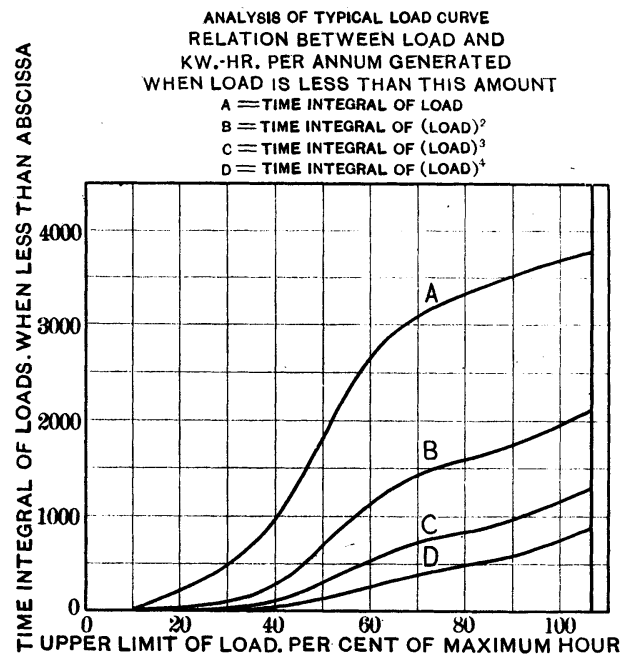

FIg. 10 
as per the load curve, operating and fixed costs given above. The solid lines represent the costs when overloads are secured without the use of inefficient means. However, to determine the effect of extra poor economy at overloads the dotted curves were compiled in which the costs of load losses etc., at overload are proportioned to the square, the cube, and the fourth power of the load.

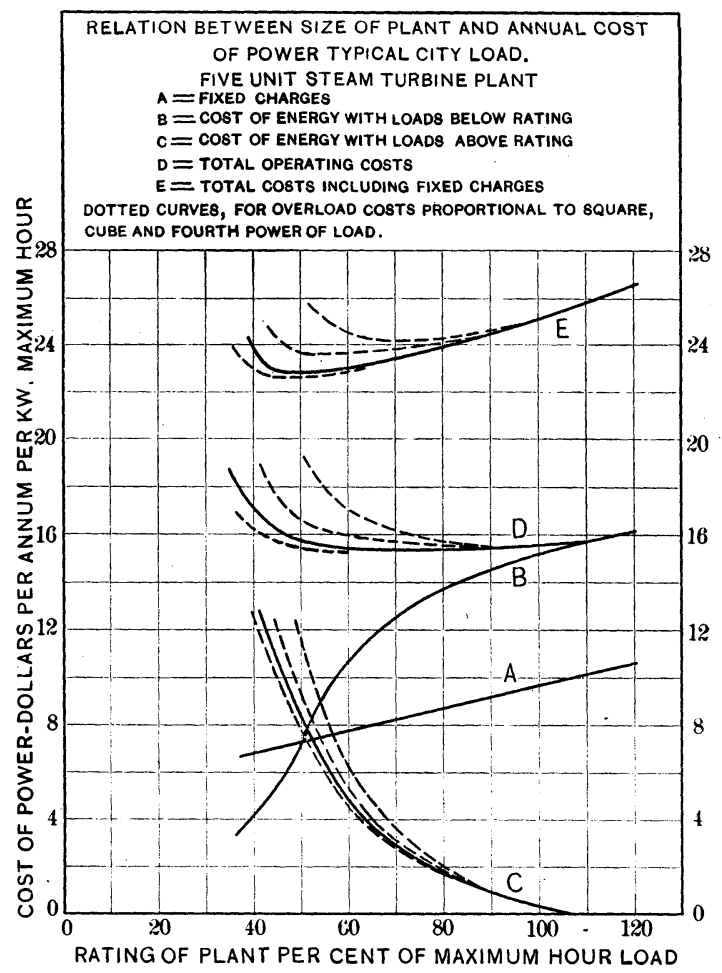

FIr. 11

In all of the comparisons for these curves the overload costs have included not only that of fuel, but also that of labor and supplies. It is thus apparent that that portion of the cost of running the plant during times of overload has a tendency to be excessive for it is by no means certain that the labor costs for operation and maintenance are increased at overloads in the same degree as that of coal. The curves in Figs. 10 to 12 are thus conservative. A glance at Figs. 13 and 14 will show the 
RELATION BETWEEN SIZE OF PLANT AND COST OF POWER PER KW. -HR. TYPICAL CITY LOAD. FIVE UNIT BTEAM TURBINE PLANT

$A$ E FIXED CHARGES D = TOTAL OPERATING COBTS

DOTTED CURVES, FOR OVERLOAD COSTS PROPORTIONAL TO SQUARE,

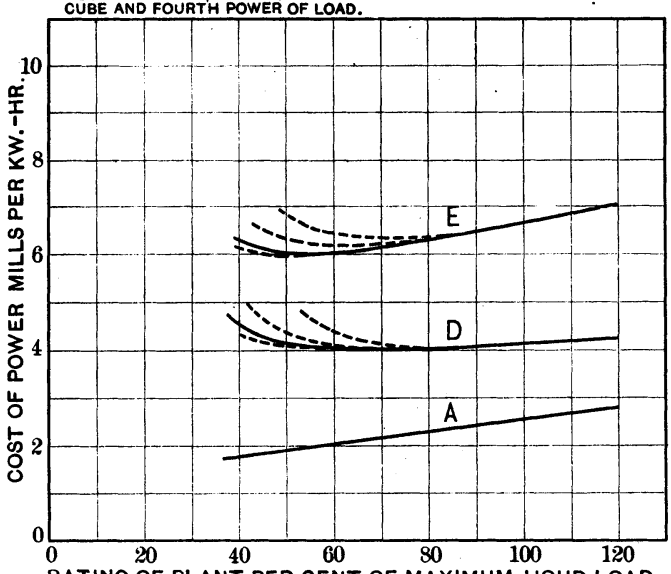

RATING OF PLANT PER CENT OF MAXIMUM HOUR LOAD

FIg. 12

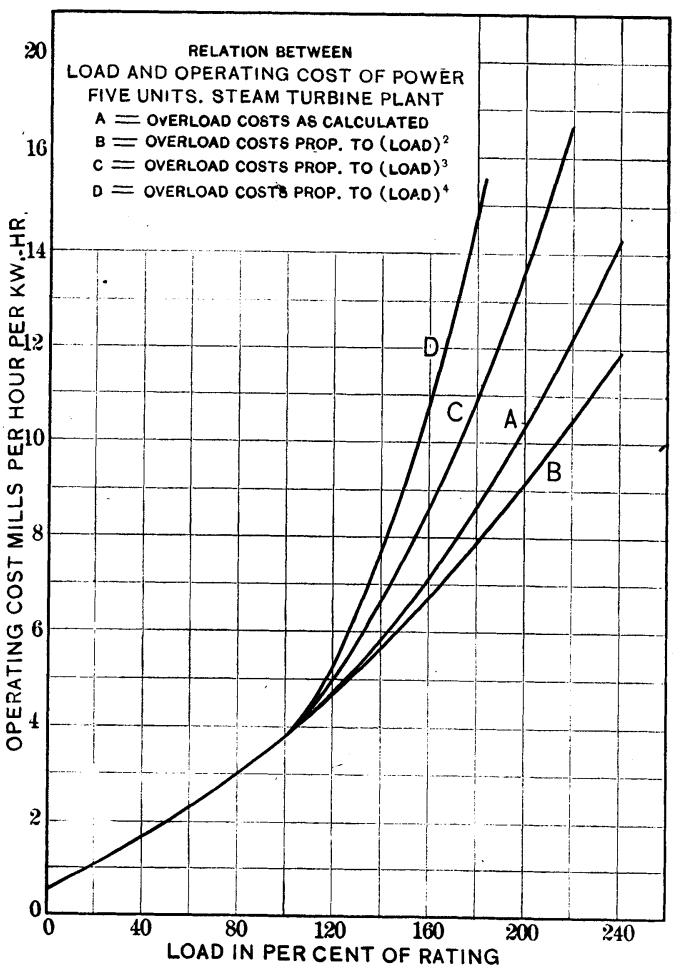

Fig. 13 
enormous increase in power costs allowed in making the determination for Figs. 10 to 12.

In spite of very lárge costs at overload, it is seen (Figs. 11 and 12) that there is actually a reduction in operating costs with a reduction in rating, due to the fact that the saving in no-load losses more than counterbalances the effect of the cost of overload losses. With fourth power costs, this reduction continues to only about 85 per cent rating but in other cases it continues

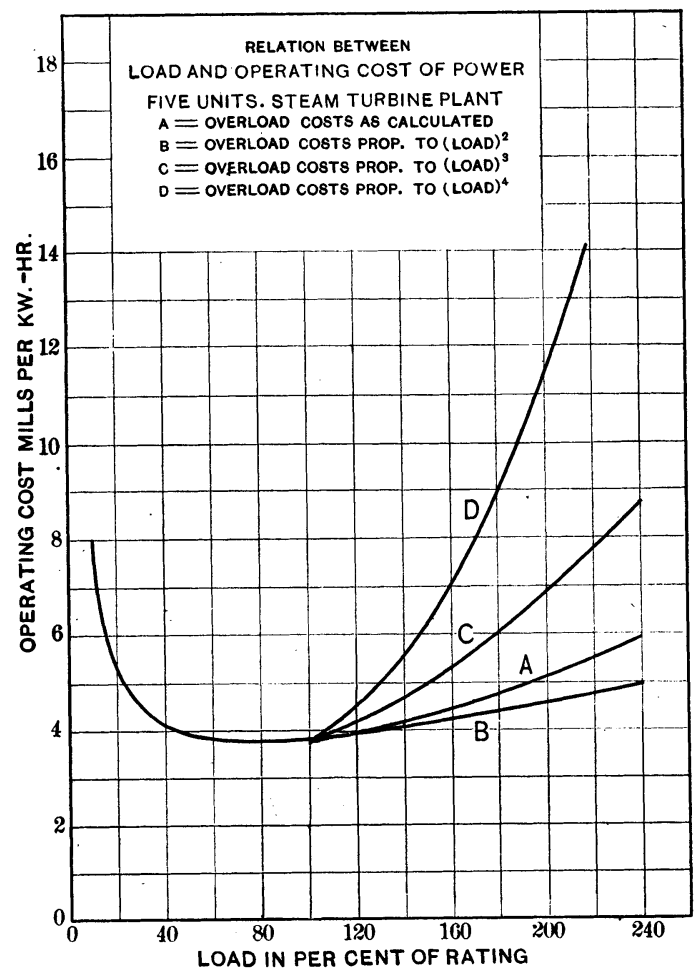

FIG. 14

to even lower ratings. Where the saving in fixed charges is added the resultant costs show reduction for ratings down to 70 per cent even with the worst possible case, while under the probable conditions the improvement continues down to $\mathbf{5 0}$ per cent rating. It is quite striking that with a very wide range of poor economy at overload a very material reduction in total costs of power may be secured by running the plant at enormous overloads during the winter peak loads, the limit being only that of available apparatus. 
At 60 per cent plant rating the maximum load on the turbine room is about 170 per cent while that on the boiler room is about 200 per cent. In the turbine room these overloads are not possible at present but there should be no difficulty in securing them if poor economy is allowable.

In order to insure against the possibility of one unit being out of service during the peak load at any time the overload capacity of the prime movers should be sufficient to cover the additional load per unit occasioned by such failure. In the case studied for a five-unit plant rated at 60 per cent of maximum hour, the maximum capacity to cover this insurance should be 210 per cent of normal rating. In the boiler room the large number of units makes the additional capacity unnecessary. On account of the fact that this extra capacity for insurance purposes may never be called upon, the operating cost when it is used is of no importance whatever.

In the boiler room it is possible even now to secure greater overloads than called for, even without material reduction in economy. Some gain in powar cost may be made by reducing the boiler equipment, but only about one-half to two-thirds of that obtained by reducing the entire plant.

To sum up the matter, it appears that under ordinary city load conditions, where the maximum loads appear only a few times a year, the power plant should be of such size that it will run at the maximum possible overload during these peaks, with sufficient margin for insurance, and that a large sacrifice in overload economy may be allowed if by so doing this overload capacity can be secured. 